\title{
Ionized calcium requirement of rumen cellulolytic bacteria
}

\author{
M. S. Morales ${ }^{1}$ and B. A. Dehority ${ }^{2}$ \\ Department of Animal Sciences, Ohio Agricultural Research and Development Center, The Ohio State University, Wooster 44691
}

\begin{abstract}
Ionized calcium $\left(\mathrm{Ca}^{+2}\right)$ appears to be required by the 3 predominant species of rumen cellulolytic bacteria, Fibrobacter succinogenes, Ruminococcus flavefaciens, and Ruminococcus albus. The present study evaluated the role of ionized calcium in growth and cellulose digestion. Maximum growth or rate and extent of digestion and lag time were the criteria used to evaluate $\mathrm{Ca}^{+2}$ requirements. All cultures except $F$. succinogenes A3c grew when repeatedly transferred in a medium without added $\mathrm{Ca}^{+2}$. As $\mathrm{Ca}^{+2}$ concentration increased in cellobiose medium, the rate of growth increased and lag time decreased for $F$. succinogenes A3c, whereas F. succinogenes $\mathrm{S} 85$ exhibited increases in both maximum growth and rate of growth. No responses in any of the criteria were observed for the ruminococci in cellobiose medium. Both strains of $F$. succinogenes had an absolute requirement for $\mathrm{Ca}^{+2}$ with cellulose as the only substrate. For strain A3c the requirement was 0.36 to $0.42 \mathrm{~m} M$ and for $\mathrm{S} 85,>0.64 \mathrm{~m} M$. Increases in extent of cellulose degradation occurred with all strains of ruminococci as $\mathrm{Ca}^{+2}$ concentration increased; however, degradation in $\mathrm{Ca}^{+2}$-free medium was similar to that of F. succinogenes with $\mathrm{Ca}^{+2}$. Although the ruminococci presumably have cellulosomes that require $\mathrm{Ca}^{+2}$ in their structure, such was not evident in our studies. The function of $\mathrm{Ca}^{+2}$ in cellulose degradation by $F$. succinogenes is unknown, but may be related to the secretion or activation of their cellulolytic enzymes. Based on reported concentrations of $\mathrm{Ca}^{+2}$ in the rumen, it seems unlikely that an in vivo deficiency would occur for these bacteria.
\end{abstract}

Key words: calcium requirement, cellulolytic bacteria, rumen

\section{INTRODUCTION}

In modern dairy cattle feeding systems, calcium is supplemented to meet the requirements of the animal

\footnotetext{
Received February 15, 2009.

Accepted June 16, 2009.

${ }^{1}$ Present address: Departamento Fomento de la Producción Animal, Facultad de Ciencias Veterinarias y Pecuarias, Universidad de Chile, Santa Rosa 11,375, La Pintana, Santiago, Chile; e-mail: smorales@ uchile.cl.

${ }^{2}$ Corresponding author: dehority.1@osu.edu
}

without consideration for requirements of the ruminal microorganisms. Commonly used Ca supplements (dicalcium phosphate, calcium carbonate) have low ruminal reactivity, and $\mathrm{Ca}$ in alfalfa, a common source of $\mathrm{Ca}$ in lactation diets, has variable availability because much is in the form of insoluble Ca oxalate (Ward and Harbers, 1982). In studies of the interactions of Ca, fatty acid concentration, and fiber digestion by ruminal microbes, Jenkins and Palmquist (1982) showed that supplementing ruminal incubations containing tallow with dicalcium phosphate did not change ruminal insoluble calcium soap formation or fiber digestibility, whereas supplying ionized $\mathrm{Ca}\left(\mathrm{Ca}^{+2}\right)$ as $\mathrm{CaCl}_{2}$ increased insoluble soap formation and improved cell wall digestibility as early as $6 \mathrm{~h}$ of incubation. Palmquist et al. (1986) reported that digestion of NDF by ruminal bacteria in sacco was more rapid during the initial $12 \mathrm{~h}$ of digestion when the ionized $\mathrm{Ca}$ concentration $\left(\left[\mathbf{C a}^{+2}\right]\right)$ of ruminal contents was $1.82 \mathrm{~m} M$ compared with 0.6 to $1.2 \mathrm{mM}$. These authors also showed that the $\left[\mathrm{Ca}^{+2}\right]$ of ruminal contents was influenced by the form (insoluble vs. soluble) of Ca supplemented and by ruminal $\mathrm{pH}$. These observations led us to hypothesize that availability of $\mathrm{Ca}^{+2}$ may play an important role in the interactions of cellulolytic ruminal microorganisms with their substrate.

Fibrobacter succinogenes, Ruminococcus albus, and Ruminococcus flavefaciens are the predominant cellulolytic bacteria that have been cultured from the rumen (Miron et al., 2001; Russell, 2002). With the discovery of the cellulosome in Clostridium thermocellum by Bayer and coworkers (Bayer et al., 2004), the cellulolytic enzymes and the proteins mediating attachment to the substrate were found to be part of an integrated system secreted by the bacterium. These discoveries provided a new approach to study the mechanisms that rumen bacteria use to degrade the insoluble carbohydrates, leading to characterization of molecular structures that have different systems of attachment and substrate degradation. Cellulosomes, fimbriae (also called pili), and glycocalyx are the different types of substrate attachment systems described in rumen cellulolytic bacteria (Miron et al., 2001). Ruminoccocus albus has cellulosomal-like mechanism and fimbriae as attachment systems, $R$. flavefaciens has cellulosome and glycocalyx, and F. suc- 
cinogenes apparently has only glycocalyx (Chesson and Forsberg, 1997; Ohara et al., 2000; Miron et al., 2001; Rincon et al., 2001; Bayer et al., 2004). Many portions of the cellulosome, fimbriae, and glycocalyx structures are known to bind $\mathrm{Ca}^{+2}$, and this may influence the molecular stability or structure and perhaps also the activity of many enzymes (Choi and Ljungdahl, 1996; Mitsumori and Minato, 2000; Ohara et al., 2000; Lytle et al., 2001; Rincon et al., 2001). There is no information related to $\mathrm{Ca}^{+2}$ requirements for either $R$. albus or $R$. flavefaciens. For F. succinogenes, only the total Ca requirement for growth is available (Bryant et al., 1959). Thus, this study investigated the $\mathrm{Ca}^{+2}$ requirements for the 3 predominant cultured rumen cellulolytic bacteria. To ensure that studies of requirements for cellulose degradation were not influenced by growth requirements, it was necessary to establish first the requirements for growth. We hypothesized that all 3 species require $\mathrm{Ca}^{+2}$ for growth, cellulose degradation, or both, and that the requirements among species differ.

\section{MATERIALS AND METHODS}

Bacterial species and strains utilized were Fibrobacter succinogenes (FS) strains S85 (FS-S85; Bryant and Doetsch, 1954) and A3c (FS-A3c; Dehority, 1963); Ruminococcus albus (RA) strains 7 (RA-7; Bryant et al., 1958) and 8 (RA-8; Hungate and Stack, 1982); and Ruminococcus flavefaciens (RF) strains B34b (RFB34b; Dehority, 1963) and C94 (RF-C94; Bryant et al., 1958). Ruminococcus albus was obtained from $\mathrm{M}$. Morrison's laboratory (Ohio State University); the other cultures were obtained from rumen-glucose-cellobiose agar slants (Bryant and Burkey, 1953) stored at $-60^{\circ} \mathrm{C}$ in the laboratory of B. A. Dehority. Transfers were made to fresh slants, which were incubated at $39^{\circ} \mathrm{C}$ and transferred several times until cultures showed active growth. At the time that strains were being studied, cultures were transferred daily. Those strains not in use were maintained at $5^{\circ} \mathrm{C}$ and transferred every 3 to $4 \mathrm{~d}$.

Inocula were prepared from bacteria growing in $\mathrm{Ca}^{+2}-$ limited cellobiose media $\left(0.04 \mathrm{mM} \mathrm{Ca}{ }^{+2}\right)$; when optical density (OD) reached 0.6 to 0.7 , cultures were added to $\mathrm{Ca}^{+2}$-free media in sufficient amount to attain 0.1 OD; then, $0.1 \mathrm{~mL}$ was taken to inoculate each experimental tube (9 $\mathrm{mL}$ of medium).

For $\mathrm{NH}_{3}$-free cellulose medium the procedure to prepare the inocula was similar, with a slight variation; inocula (at least 8 tubes) were grown in a $\mathrm{Ca}^{+2}$-limited medium $(0.04 \mathrm{mM})$. When OD was 0.6 to 0.7 , the tubes were centrifuged ( 15 to $20 \mathrm{~min}, 900 \times g$ ) and the supernatant was decanted and discarded. Phosphate buffer was added to resuspend the bacterial cells, the culture was mixed, OD determined, and enough buffer was added to reach 0.7 to $0.75 \mathrm{OD}$. Then, $1 \mathrm{~mL}$ was used to inoculate each culture tube of $\mathrm{NH}_{3}$-free cellulose medium.

To maintain anaerobic conditions, preparation of media, inoculations, and transfers were carried out under a stream of $\mathrm{O}_{2}$-free $\mathrm{CO}_{2}$, obtained by passing commercial $\mathrm{CO}_{2}$ through a heated glass column filled with reduced copper turnings (Hungate, 1950).

All chemicals used were reagent grade; however, in media without added $\mathrm{Ca}$ (Ca-free medium), $\left[\mathrm{Ca}^{+2}\right]$ ranged from 0.0032 to $0.014 \mathrm{mM}$ and [Ca] was 0.046 to $0.056 \mathrm{~m} M$. This resulted from trace amounts of Ca contained in the other mineral sources included in the basal medium. Water was deionized in the laboratory (Nanopure Diamond Life Science (UV/UF), Ultrapure water system, Barnstead International, Dubuque, IA).

For the studies of $\mathrm{Ca}^{+2}$ requirement, the complete anaerobic medium of Scott and Dehority (1965) was used at the recommended Ca concentration $(0.24 \mathrm{mM}$; Bryant et al., 1959). Cellobiose (0.5\%) or cellulose (0.75\%) (Sigmacell-20, Sigma Chemical, St. Louis, MO; ball-milled for $24 \mathrm{~h}$, ) served as energy substrate. Growth was monitored by measuring absorbance at 600 $\mathrm{nm}$ with a Spectronic 20 spectrophotometer (Bausch and Lomb, Rochester, NY). Cellulose degradation was determined by measuring residual cellulose as described by Hiltner and Dehority (1983). Briefly, culture tubes were centrifuged at approximately $900 \times g$ for $10 \mathrm{~min}$, the supernatant removed, and acid detergent fiber solution was added to the residue. The mixture was heated at $100^{\circ} \mathrm{C}$ for $60 \mathrm{~min}$ and, using centrifugation, washed twice with boiling deionized water. The residue was transferred to a tared test tube with deionized water, centrifuged, and the supernatant was removed. The tube with residue was dried in a $100^{\circ} \mathrm{C}$ oven overnight, placed in a desiccator until cool, and weighed. Digestion was calculated by the difference between unincubated and incubated fermentation tubes.

Ionized calcium in the media was determined using an ion-meter (Accumet AR25, Fisher Scientific, Pittsburgh, PA) with a $\mathrm{Ca}^{+2}$-specific electrode (Thermo Orion, model 93-20, Thermo Fisher Scientific, Beverly, MA) and a single junction reference electrode (Thermo Orion, model 90-01, Thermo Fisher Scientific). Total Ca concentration was determined by atomic absorption spectrophotometry (Varian Spectr AA200, Varian, Palo Alto, CA), following the specific instructions from the instrument manufacturer. To remove all other possible mineral contamination, glassware was washed, soaked in $20 \% \mathrm{HCl}$ for $24 \mathrm{~h}$, and then rinsed 3 times with deionized water.

For growth in cellobiose liquid medium, experiments with the different bacterial species and strains were run in duplicate with one replicate. Growth was mea- 
sured from 0 to $48 \mathrm{~h}$ or until the maximum growth was reached, because of variation among species and strains in terms of growth velocity. For cellulose degradation in complete cellulose medium, all experiments were run with duplicate tubes. Experiments with both strains of FS and RF were replicated twice, whereas RA strains were replicated only once. Strain RA-7 was able to grow and degrade cellulose in a cation-depleted medium; however, strain RA-8 grew very slowly and degraded a limited amount of cellulose regardless of $\mathrm{Ca}^{+2}$ concentration. Because of the differences in degradation behavior, sampling times varied among species and strains. With $\mathrm{NH}_{3}$-free cellulose medium, experiments with both FS strains were run in duplicate. Only one replicate was run with FS-A3c, whereas 2 replicates were run with FS-S85. Sampling times for replicate 1 were $0,12,24$, and $48 \mathrm{~h}$; however, because initiation of degradation was rather slow, $0,18,24$ and $48 \mathrm{~h}$ were used as sampling times for replicate 2 .

\section{Experimental Design}

To determine $\mathrm{Ca}^{+2}$ requirements for growth and cellulose degradation, an incomplete $[2(3) \times 6 / 8]$ factorial design was used; factors were strains (2) within species (3), and 6 to 8 concentrations of $\mathrm{Ca}^{+2}$. The 2 strains of each species were run simultaneously, but each species was run separately; replicates were blocks; tubes were the experimental unit in growth experiments because absorbance of individual tubes was measured. For cellulose degradation, where different tubes were sampled at different chronological times, 2 racks were incubated in each replicate; the duplicate rack was the experimental unit. Each rack contained tubes to establish the basal cellulose content at time 0 for each treatment, and 4 tubes for each $\left[\mathrm{Ca}^{+2}\right]$ at each of the 3 sampling times. Control (uninoculated) tubes were incubated simultaneously.

For cellulose degradation in $\mathrm{NH}_{3}$-free medium, a factorial $2 \times 8$ design was used. Strains FS-A3c and FS-S85 were each assigned to 8 different $\left[\mathrm{Ca}^{+2}\right]$. As in other experiments, replicates were blocks. Racks were the experimental unit because cellulose degradation was measured in each.

\section{Statistical Analysis}

Growth data and cellulose degradation were fitted mathematically with a logistic model (Zwietering et al., 1990): $\mathrm{Y}=\mathrm{A} /(1+\exp \{[(4 \times \mathrm{B}) / \mathrm{A}] \times(\mathrm{C}-$ time $)+$ $2\})$, where $\mathrm{Y}$ represents growth or cellulose degradation, using nonlinear regression analysis (NLIN PROC; SAS Institute, 1999) to determine A [maximum growth (maximum absorbance) or extent of degradation (mg degraded)]; B [growth rate (absorbance units/h) or cellulose degradation rate $(\mathrm{mg}$ degraded $/ \mathrm{h})]$; and $\mathrm{C}$, the lag time (h).

Parameters A, B, and $\mathrm{C}$ weighted by the reciprocals of their standard errors were used for ANOVA analysis, as described below.

\section{Growth Data}

Least squares means (LSM) were compared with linear and quadratic contrasts (PROC MIXED, SAS Institute, 1999). Fixed effects were $\left[\mathrm{Ca}^{+2}\right]$, species, strain within species, and the interaction of strain within species $\times\left[\mathrm{Ca}^{+2}\right]$. Random effects were block within species and tube within block. The extended and reduced models were compared and, because they were different $(P<0.05)$, the extended model was used. Homogeneity of variance evaluation showed that an unstructured variance test for analysis of $\mathrm{A}, \mathrm{B}$, and $\mathrm{C}$ parameters for the $\left[\mathrm{Ca}^{+2}\right]$ growth response should be used. Parameters used to characterize the requirement of $\mathrm{Ca}^{+2}$ for growth were the maximum growth, rate of growth, and lag time. When the linear effect for any of these was significant, it was not possible to estimate a requirement because an end-point was not attained. When a quadratic effect was significant, nonlinear analysis was used to define the break-point and the plateau of the function (PROC NLIN, SAS Institute, 1999). When this method did not have a solution, the maximum of the first derivative of the quadratic function (PROC REG, SAS Institute, 1999) was used to estimate requirements.

Data for the RA-8 growth curve did not fit the logistic model, so these data were not included in the overall analysis. However, data were analyzed by linear regression to determine rates of growth (PROC REG, SAS Institute, 1999); then the "b" coefficients or slopes obtained were evaluated by ANOVA. If significant differences were found, the LSM difference test was applied (GLM, SAS Institute, 1999) to identify effect of $\left[\mathrm{Ca}^{+2}\right]$ on rate of growth. Maximum growth obtained from raw data was analyzed by ANOVA, and no differences among $\left[\mathrm{Ca}^{+2}\right]$ were found $(P>0.05)$.

The extended model used for growth studies was

$$
\begin{gathered}
\mathrm{Y}=\left[\mathrm{Ca}^{+2}\right]+\text { species }+ \text { strain }(\text { species })+\text { block } \\
+ \text { tube }(\text { block })+\left[\mathrm{Ca}^{+2}\right] \times \text { strain }(\text { species })+\text { error. }
\end{gathered}
$$

\section{Cellulose Degradation}

The profile of the data from cellulose degradation was similar to the growth curves. Because the inoculum was small, bacteria grew by using energy derived from cellulose degradation. The function to characterize the 
Table 1. Calculated and measured concentrations of $\mathrm{Ca}$ and $\mathrm{Ca}^{+2}$ in cellobiose and cellulose media obtained by adding varying volumes of $0.1 \mathrm{M} \mathrm{CaCl}_{2}$

\begin{tabular}{lcccc}
\hline $\begin{array}{l}0.1 \mathrm{M} \mathrm{CaCl} \text { added, } \\
\mathrm{mL} / \mathrm{L} \text { of medium }\end{array}$ & $\begin{array}{c}\text { Calculated } \mathrm{Ca}^{+2} \\
\text { concentration, } \mathrm{m} M\end{array}$ & $\begin{array}{c}\text { Measured } \mathrm{Ca}^{+2} \\
\text { concentration, }{ }^{1} \mathrm{~m} M\end{array}$ & $\begin{array}{c}\text { Calculated Ca } \\
\text { concentration, } \mathrm{m} M\end{array}$ & $\begin{array}{c}\text { Measured Ca } \\
\text { concentration, }{ }^{2} \mathrm{~m} M\end{array}$ \\
\hline 0 & 0 & $0.0032-0.014$ & 0 & 0.056 \\
0.47 & 0.02 & 0.029 & 0.047 & 0.10 \\
0.93 & 0.04 & 0.045 & 0.10 & 0.16 \\
1.87 & 0.08 & 0.078 & 0.19 & 0.26 \\
3.73 & 0.16 & 0.178 & 0.37 & 0.45 \\
7.46 & 0.32 & 0.35 & 0.75 & 0.83 \\
14.92 & 0.64 & 0.63 & 1.49 & 1.60 \\
\hline
\end{tabular}

${ }^{1}$ Measured with an ion electrode.

${ }^{2}$ Measured by atomic absorption spectrophotometry.

bacterial response of cellulose degradation to increasing $\left[\mathrm{Ca}^{+2}\right]$ also was the logistic model of Zwietering et al. (1990). Because no rapid degradation or disappearance of crystalline cellulose occurred, other models were discarded as not appropriate. Usually, nutrient degradation in the rumen is described by first-order kinetics or the model that includes a lag time (Noziere and Michalet-Doreau, 2000), but the data did not fit either of these models. Because of differing characteristics of the various bacterial species that required sampling at different times, it was not possible to use NLIN MIXED for data analysis. Therefore, NLIN PROC from SAS was used.

All the species and strains evaluated fit the Zwietering model $(P<0.05)$, with the exception of RA-8. Parameters A, B, and $\mathrm{C}$ and their respective standard errors for each tube were obtained; parameters were weighted by the reciprocals of the standard errors and analyzed by ANOVA using PROC MIXED (SAS Institute, 1999). In the statistical model, $\left[\mathrm{Ca}^{+2}\right]$, species, strain within species, and the interaction of strain within species $\times\left[\mathrm{Ca}^{+2}\right]$ were considered as fixed effects; block and tubes were random effects.

The extended and reduced models were compared. Because these were not different, the reduced model was used for ANOVA. Least squares means were compared by linear and quadratic contrasts (PROC MIXED, SAS Institute, 1999). Quadratic functions were estimated with PROC REG (SAS Institute, 1999). The breakpoint was determined by the maximum of the first derivative of the quadratic function. The reduced model for cellulose degradation used was $\mathrm{Y}=\left[\mathrm{Ca}^{+2}\right]+$ species + strain (species) $+\left[\mathrm{Ca}^{+2}\right] \times$ strain(species $)+$ error.

Strain RA-8 did not fit the logistic model and in this case linear regression was used to establish the rate of degradation (PROC REG, SAS Institute, 1999); the slopes for the various $\left[\mathrm{Ca}^{+2}\right]$ obtained were not different. The extent of degradation obtained at the last sampling was used to evaluate maximum degradation, which was found not to differ among $\left[\mathrm{Ca}^{+2}\right]$.

\section{Cellulose Degradation by FS in $\mathrm{NH}_{3}$-Free Medium}

In the case of FS-A3c $\mathrm{NH}_{3}$-free experiments, the data from $0.02 \mathrm{mM} \mathrm{Ca}^{+2}$ did not fit the logistic model or the linear regression. Then, the LSM of cellulose degradation were calculated and separated (DIFF option) to establish differences in degradation among sampling times. The reduced statistical model used was $\mathrm{Y}=$ $\left[\mathrm{Ca}^{+2}\right]+$ strain $+\left[\mathrm{Ca}^{+2}\right] \times$ strain + error.

\section{RESULTS}

\section{Total [Ca] and $\left[\mathrm{Ca}^{+2}\right]$ in Growth and Cellulose Media}

The concentrations of $\mathrm{Ca}$ and $\mathrm{Ca}^{+2}$ in both cellobiose and cellulose media were measured, using an ion electrode to measure $\left[\mathrm{Ca}^{+2}\right]$ and atomic absorption spectrophotometry for [Ca] (Table 1). Also shown are calculated concentrations based on the amount of added $\mathrm{CaCl}_{2}$. In general, measured $[\mathrm{Ca}]$ and $\left[\mathrm{Ca}^{+2}\right]$ were slightly higher than the calculated values.

\section{Growth Requirements in Cellobiose Media}

Maximum growth of FS-A3c responded neither linearly nor quadratically to increased $\left[\mathrm{Ca}^{+2}\right]$ (Table 2). However, growth rate increased linearly $(P=0.0027)$ and quadratically $(P=0.0075)$ as $\left[\mathrm{Ca}^{+2}\right]$ increased, and lag time decreased linearly $(P=0.0084)$. The $\mathrm{Ca}^{+2}$ requirements for growth of FS-A3c cannot be estimated from these data because the linear growth rate and lag time did not reach end points. Higher concentrations of $\mathrm{Ca}^{+2}$ must be used to define requirements. Because rate of growth responded quadratically, the requirement for $\left[\mathrm{Ca}^{+2}\right]$ could be estimated to be $0.43 \mathrm{mM}$, using the maximum of the first derivative of the quadratic function $\left(P=0.0001, \mathrm{r}^{2}=0.72\right)$. In contrast, maximum growth of FS-S85 increased both linearly $(P=0.0012)$ and quadratically $(P=0.032)$ as $\left[\mathrm{Ca}^{+2}\right]$ increased. As with FS-A3c, rate of growth increased linearly $(P=$ $0.003)$. Neither linear nor quadratic responses to in- 
Table 2. Effects of different $\mathrm{Ca}^{+2}$ concentrations $\left(\left[\mathrm{Ca}^{+2}\right], \mathrm{m} M\right)$ on growth of Fibrobacter succinogenes strains A3c and S85 in liquid media with cellobiose as the energy source ${ }^{1}$

\begin{tabular}{lccc}
\hline$\left[\mathrm{Ca}^{+2}\right], \mathrm{m} M$ & Maximum growth & & \\
\hline F. succinogenes A3c & & Rate of growth & \\
0 & $1.43 \pm 0.06$ & & Lag time, $\mathrm{h}$ \\
0.02 & $1.39 \pm 0.04$ & $0.14 \pm 0.018$ & $17.2 \pm 1.2$ \\
0.08 & $1.37 \pm 0.03$ & $0.18 \pm 0.016$ & $17.0 \pm 1.1$ \\
0.16 & $1.50 \pm 0.04$ & $0.18 \pm 0.015$ & $15.0 \pm 0.9$ \\
0.32 & $1.40 \pm 0.07$ & $0.20 \pm 0.025$ & $17.4 \pm 1.2$ \\
0.36 & $1.46 \pm 0.03$ & $0.20 \pm 0.016$ & $14.0 \pm 0.9$ \\
0.64 & $1.51 \pm 0.03$ & $0.19 \pm 0.016$ & $11.1 \pm 0.9$ \\
Linear & 0.1608 & 0.0027 & 0.0084 \\
Quadratic & 0.7988 & 0.0075 & 0.5403 \\
F. succinogenes S85 & & & \\
0 & $1.27 \pm 0.06$ & $0.11 \pm 0.017$ & $14.3 \pm 1.1$ \\
0.02 & $1.27 \pm 0.06$ & $0.11 \pm 0.016$ & $15.2 \pm 1.3$ \\
0.08 & $1.26 \pm 0.04$ & $0.14 \pm 0.016$ & $14.4 \pm 0.9$ \\
0.16 & $1.37 \pm 0.05$ & $0.13 \pm 0.021$ & $13.9 \pm 0.9$ \\
0.32 & $1.44 \pm 0.08$ & $0.15 \pm 0.016$ & $13.9 \pm 1.2$ \\
0.36 & $1.34 \pm 0.03$ & $0.14 \pm 0.016$ & $13.5 \pm 0.9$ \\
0.64 & $1.37 \pm 0.04$ & 0.0039 & 0.1065 \\
Linear & 0.0012 & 0.2221 & 0.1455 \\
Quadratic & 0.0316 & & \\
\hline
\end{tabular}

${ }^{1}$ For each strain, maximum growth, rate of growth, and lag time were evaluated by linear and quadratic contrasts; $P$-values are presented.

${ }^{2}$ Absorbance units.

${ }^{3}$ Absorbance units/h.

creasing $\left[\mathrm{Ca}^{+2}\right]$ for lag time were observed for FS-S85. Because FS-S85 responded linearly and quadratically to increasing $\mathrm{Ca}^{+2}$ concentrations for maximum growth, its requirement was estimated to be $0.47 \mathrm{mM}(P=$ $\left.0.02 ; \mathrm{r}^{2}=0.27\right)$. No requirement for rate of growth can be estimated. Similar to FS-A3c, higher $\left[\mathrm{Ca}^{+2}\right]$ will be needed in future research to determine the maximum growth response to $\mathrm{Ca}^{+2}$.

For RA-7, maximum growth and rate of growth did not respond significantly to increased $\left[\mathrm{Ca}^{+2}\right]$ in cellobiose medium $(P>0.05$; data not shown). A linear tendency for maximum growth $(P=0.09)$ and a quadratic tendency for rate of growth $(P=0.06)$ were observed. Lag times decreased linearly with increasing $\left[\mathrm{Ca}^{+2}\right](P$ $=0.006)$. An unexpected response was obtained from RA-8 in that it grew very slowly and did not reach a maximum absorbance $>0.56$, the lowest among all strains studied. Growth of this strain did not fit the logistic function; therefore, it was evaluated separately. Values for RA-8 were adjusted to a linear function $(P$ $<0.05)$; both the model and the slope were significant, but the intercept was not. When rates of growth represented by the slopes of the linear functions were compared among $\left[\mathrm{Ca}^{+2}\right]$, RA-8 showed the highest rate of growth at 0.32 and $0.36 \mathrm{mM}\left[\mathrm{Ca}^{+2}\right]$.

Increasing $\left[\mathrm{Ca}^{+2}\right]$ did not affect maximum growth, rate of growth, or lag time for either of the RF strains (B34b or C94). Consistently, maximum growth of RF strains occurred with $\mathrm{Ca}^{+2}$-free media, and this response was confirmed with successive transfers in $\mathrm{Ca}^{+2}$-free media.
In 14 fermentations with FS-A3c grown in $\mathrm{Ca}^{+2}$-free medium (not all data reported), growth was observed in only 3 experiments. In those experiments where FSA3c did not grow, media contained $0.0138 \mathrm{mM} \mathrm{Ca}^{+2}$ and $0.053 \mathrm{mM}$ total $\mathrm{Ca}$. When a consecutive bacterial transfer experiment was performed, in which all strains were transferred from $\mathrm{Ca}^{+2}$-free to $\mathrm{Ca}^{+2}$-free medium, FS-A3c did not grow when $\mathrm{Ca}^{+2}$ was $\leq 0.014 \mathrm{~m} M$ and total Ca was $\leq 0.046 \mathrm{~m} M$ (Morales, 2005). However, when $\left[\mathrm{Ca}^{+2}\right]$ in the initial medium was $\geq 0.02 \mathrm{~m} M$, FSA3c grew normally until the seventh or eighth transfer into $\mathrm{Ca}^{+2}$-free media, after which growth ceased. Thus, FS-A3c was documented to require $\mathrm{Ca}^{+2}$ for growth, but at a very low concentration. Strain FS-S85, as well as all other organisms in this study, always grew under the conditions of repeated transfer in $\mathrm{Ca}^{+2}$-free media (Morales, 2005).

When FS-A3c did grow in $\mathrm{Ca}^{+2}$-free media, we observed maximum growth (near 1.4 absorbance). Upon microscopic examination, highly pleomorphic cells were observed in the $\mathrm{Ca}^{+2}$-free media. After the experiment was completed, analysis revealed that the medium contained $0.019 \mathrm{mM} \mathrm{Ca}{ }^{+2}$. A second analysis of the " $\mathrm{Ca}^{+2}$-free" medium used in this experiment showed that $\left[\mathrm{Ca}^{+2}\right]$ in all media were similar and higher than estimated, probably because of Ca contamination from the water supply. Therefore, in subsequent experiments, only HPLC water (Fisher W5-4, Fisher Scientific) documented to be free of $\mathrm{Ca}$ was used to prepare media. Also, by using a very small inoculum $(0.1 \mathrm{~mL}$ 
Table 3. Cellulose degradation by Fibrobacter succinogenes strains A3c and S85 incubated with different concentrations of ionized $\mathrm{Ca}^{+2}\left[\mathrm{Ca}^{+2}\right]^{1}$

\begin{tabular}{|c|c|c|c|}
\hline$\left[\mathrm{Ca}^{+2}\right], \mathrm{m} M$ & Maximum degradation $^{2}$ & Rate of degradation ${ }^{3}$ & Lag time, $\mathrm{h}$ \\
\hline \multicolumn{4}{|c|}{ F. succinogenes A3c } \\
\hline 0 & No degradation & & \\
\hline 0.04 & $21.0 \pm 0.26$ & $0.33 \pm 0.18$ & $49.0 \pm 6.24$ \\
\hline 0.06 & $14.0 \pm 0.07$ & $0.99 \pm 0.11$ & $37.5 \pm 2.78$ \\
\hline 0.08 & $21.5 \pm 0.09$ & $0.69 \pm 0.29$ & $35.5 \pm 2.87$ \\
\hline 0.12 & $20.6 \pm 0.11$ & $0.51 \pm 0.20$ & $16.4 \pm 4.03$ \\
\hline 0.36 & $32.0 \pm 0.07$ & $2.00 \pm 0.08$ & $28.8 \pm 2.72$ \\
\hline Linear & $<0.0001$ & $<0.0001$ & 0.6165 \\
\hline Quadratic & Not solved & Not solved & Not solved \\
\hline \multicolumn{4}{|c|}{ F. succinogenes $\mathrm{S} 85$} \\
\hline 0 & No degradation & & \\
\hline 0.04 & $25.0 \pm 0.09$ & $1.11 \pm 0.18$ & $20.4 \pm 2.92$ \\
\hline 0.06 & $22.2 \pm 0.09$ & $1.24 \pm 0.37$ & $21.0 \pm 2.82$ \\
\hline 0.08 & $28.0 \pm 0.08$ & $2.48 \pm 0.28$ & $22.2 \pm 2.75$ \\
\hline 0.12 & $25.8 \pm 0.09$ & $1.25 \pm 0.46$ & $23.4 \pm 2.81$ \\
\hline 0.36 & $31.8 \pm 0.11$ & $1.45 \pm 0.25$ & $21.2 \pm 3.05$ \\
\hline Linear & Not solved & Not solved & Not solved \\
\hline Quadratic & Not solved & Not solved & Not solved \\
\hline
\end{tabular}

of bacterial culture diluted to 0.1 OD), it was possible to minimize any contribution of nutrients released from autolyzed bacteria.

\section{$\mathrm{Ca}^{+2}$ Requirement for Cellulose Degradation}

The maximum cellulose degradation and lag times were affected by $\left[\mathrm{Ca}^{+2}\right]$ in all strains except $\mathrm{RA}-8$, whereas rates of degradation were not affected by $\left[\mathrm{Ca}^{+2}\right]$ $(P>0.05)$. After removal of significant interactions for species $x$ treatment and strain within species $x$ treatment, rate of cellulose degradation was affected by $\left[\mathrm{Ca}^{+2}\right]$, but only in FS-A3c and FS-S85. Neither strain of FS degraded cellulose in the absence of supplemental $\mathrm{Ca}^{+2}$; however, maximum cellulose degradation responded irregularly to increased $\left[\mathrm{Ca}^{+2}\right]$ in both strains (Table 3). Both maximum degradation and rate of degradation increased linearly as $\left[\mathrm{Ca}^{+2}\right]$ increased $(P<$ $0.0001)$ in FS-A3c; thus, higher $\left[\mathrm{Ca}^{+2}\right]$ must be tested to establish a requirement. Although there was an effect of $\left[\mathrm{Ca}^{+2}\right]$ on maximum degradation for FS-S85, it cannot be represented by linear or quadratic adjustments because the contrast analysis had no solution $(P>0.05)$. Although lag time was affected by $\left[\mathrm{Ca}^{+2}\right]$, these did not fit linear or quadratic contrasts for FS-A3c $(P=0.62$, NS) and FS-S85 (no solution for contrasts).

The highest maximum degradation among all the strains studied was observed with RA-7 (Table 4); maximum degradation responded significantly to increasing $\left[\mathrm{Ca}^{+2}\right]$ both linearly $(P=0.0027)$ and quadratically $(P=0.037)$. Increased $\left[\mathrm{Ca}^{+2}\right]$ also decreased lag time, linearly and quadratically, in RA-7. The requirements for maximum cellulose degradation and minimum lag time were estimated to be 0.28 and $0.34 \mathrm{mM} \mathrm{Ca}{ }^{+2}$, respectively.

Calcium requirements for RA-8 were analyzed independently because response values did not fit the logistic function. When the averages for extent of degradation obtained at the final sampling time were analyzed by ANOVA, no effects of $\left[\mathrm{Ca}^{+2}\right]$ were detected $(P>0.05)$. The slope of the linear function for each $\left[\mathrm{Ca}^{+2}\right]$ (representing the rate of cellulose degradation) analyzed by ANOVA showed no differences due to $\left[\mathrm{Ca}^{+2}\right]$, thus no further analysis was made. Because of the lack of fit with the logistic function, parameter $\mathrm{C}$ (representing lag time) could not be obtained. The time of the first sampling was reported as lag time only to provide a reference for the time delay until cellulose degradation could be observed. Because cellulose degradation was so slow, it was not possible to determine the maximum cellulose degradation for RA-8. It is suspected that our culture of RA- 8 was one of the mutant types that spontaneously arises with this strain (Devillard et al., 2004).

Extents of cellulose degradation and lag times for RF-B34b and RF-C94 were both affected by increasing $\left[\mathrm{Ca}^{+2}\right]$ (Table 5); however, rates of degradation were not affected. In both strains maximum degradation increased linearly $(P<0.0001)$ as $\left[\mathrm{Ca}^{+2}\right]$ increased. Although the linear function fit the adjustment, the response was small and seemed not to reflect the biology of the response. Lag time was affected by $\left[\mathrm{Ca}^{+2}\right]$ in 
Table 4. Cellulose degradation by Ruminococcus albus strains 7 and 8 incubated with different concentrations of $\mathrm{Ca}^{+2}\left[\mathrm{Ca}^{+2}\right]$

\begin{tabular}{lccc}
\hline$\left[\mathrm{Ca}^{+2}\right], \mathrm{m} M$ & Maximum degradation $^{1}$ & Rate of degradation $^{2}$ & Lag time, $\mathrm{h}$ \\
\hline$R$. albus $7^{3}$ & & & \\
0 & $31.34 \pm 1.37$ & $1.08 \pm 0.19$ & $15.62 \pm 4.02$ \\
0.02 & $38.32 \pm 1.45$ & $1.41 \pm 0.26$ & $10.90 \pm 4.11$ \\
0.04 & $36.59 \pm 1.46$ & $1.48 \pm 0.28$ & $12.11 \pm 4.13$ \\
0.08 & $34.30 \pm 1.59$ & $1.49 \pm 0.35$ & $10.61 \pm 4.29$ \\
0.16 & $37.88 \pm 1.53$ & $1.50 \pm 0.31$ & $9.36 \pm 4.22$ \\
0.32 & $36.94 \pm 1.46$ & $1.47 \pm 0.29$ & $9.84 \pm 4.16$ \\
0.36 & $33.46 \pm 1.74$ & $1.23 \pm 0.36$ & $7.09 \pm 4.55$ \\
0.64 & $33.96 \pm 1.76$ & $1.55 \pm 0.41$ & $<.42$ \\
Linear & 0.0027 & $\mathrm{NC}$ & 0.00009 \\
Quadratic & 0.0372 & & $60^{6}$ \\
$R$. albus 8 & & $0.0285 \pm 0.016^{5}$ & 60 \\
0 & $9.80^{4}$ & $0.0418 \pm 0.017$ & 60 \\
0.02 & 15.10 & $0.0589 \pm 0.043$ & 60 \\
0.04 & 13.55 & $0.0395 \pm 0.028$ & 60 \\
0.08 & 19.68 & $0.0574 \pm 0.021$ & 60 \\
0.16 & 18.83 & $0.0854 \pm 0.026$ & 60 \\
0.32 & 26.00 & $0.0659 \pm 0.021$ & 60 \\
0.36 & 21.96 & $0.0649 \pm 0.022$ & \\
\hline
\end{tabular}

${ }^{1} \mathrm{mg}$ of cellulose.

${ }^{2} \mathrm{mg}$ of cellulose/h.

${ }^{3}$ For $R$. albus 7 , maximum degradation and lag time were evaluated by linear and quadratic contrasts; $P$ values are presented. $\mathrm{NC}=$ no contrasts analysis; no effect of $\mathrm{Ca}^{+2}$ concentrations $(P>0.05)$.

${ }^{4}$ Maximum cellulose degradation (extent of degradation obtained at the last sampling time, $275 \mathrm{~h}$ ).

${ }^{5}$ Rate of degradation (the slope of the linear regression; $P=0.064$ ).

${ }^{6} \mathrm{Lag}$ time (the time for first sampling, determined visually).

both strains, but only RF-C94 showed a quadratic response $(P=0.0007)$ by contrasts evaluation. However, lag time is not a common parameter used to measure requirements.

\section{$\mathrm{Ca}^{+2}$ Requirements of FS for Cellulose Degradation in $\mathrm{NH}_{3}$-Free Media}

Because FS was found to have an absolute, although highly variable, requirement for $\mathrm{Ca}^{+2}$ for cellulose degradation and because $\left[\mathrm{Ca}^{+2}\right]$ affected growth rate in cellobiose media, a study was designed to measure cellulose degradation in $\mathrm{NH}_{3}$-free media. This design eliminated growth as a confounding factor in the determination of $\mathrm{Ca}^{+2}$ requirement for cellulose degradation. The effects of strain, $\left[\mathrm{Ca}^{+2}\right]$ and the interaction of strain $\times$ treatment on cellulose degradation in $\mathrm{NH}_{3}$-free media were evaluated.

No cellulose degradation occurred in $\mathrm{Ca}^{+2}$-free medium for either strain of FS incubated in $\mathrm{NH}_{3}$-free medium (Table 6). Very low degradation by FS-A3c was observed with $0.02 \mathrm{mM} \mathrm{Ca}{ }^{+2}$; however, data fit neither the logistic nor linear models. Therefore, comparisons of least squares means for each sampling time were used to determine if degradation at this low $\left[\mathrm{Ca}^{+2}\right]$ differed among sampling times. Cellulose degradation was different between sampling times of 24 and 48 $\mathrm{h}$; this difference was used to estimate degradation, which was found to be $3.9 \mathrm{mg}$ at $48 \mathrm{~h}$ for FS-A3c. As $\left[\mathrm{Ca}^{+2}\right]$ increased, cellulose degradation increased, both in extent and rate of degradation. Maximum cellulose degradation increased both linearly and quadratically in FS-A3c $(P<0.0001)$, whereas in FS-S85 maximum degradation increased linearly $(P=0.0029)$ as $\left[\mathrm{Ca}^{+2}\right]$ increased. Considering the significance of the contrasts and the curve of maximum degradation versus $\left[\mathrm{Ca}^{+2}\right]$ for FS-A3c, the quadratic adjustment is more likely to define the $\mathrm{Ca}^{+2}$ requirement for maximum degradation. Thus, the $\mathrm{Ca}^{+2}$ requirement is $0.47 \mathrm{mM}$. It is not possible to calculate a requirement for FS-S85 because only the linear contrast was significant. Although the curve tended to be quadratic, high variation of the data compromises interpretation. Rate of degradation responded quadratically to increasing $\left[\mathrm{Ca}^{+2}\right]$, significant for FSA3c $(P=0.013)$ but only as a tendency for FS-S85 ( $P$ $=0.08)$. In this case, the requirement is $0.4 \mathrm{~m} M$ for rate of degradation for FS-A3c. For both strains, lag time was not affected by differing $\left[\mathrm{Ca}^{+2}\right]$.

\section{DISCUSSION}

As shown in Table 1 , the measured $\left[\mathrm{Ca}^{+2}\right]$ in the medium increased as total [Ca] increased. When the measured values of $\left[\mathrm{Ca}^{+2}\right]$ were regressed on total $[\mathrm{Ca}]$, 
Table 5. Cellulose degradation by Ruminococcus flavefaciens strains B34b and C94 incubated with different concentrations of $\mathrm{Ca}^{+2}\left[\mathrm{Ca}^{+2}\right]^{1}$

\begin{tabular}{|c|c|c|c|}
\hline$\left[\mathrm{Ca}^{+2}\right], \mathrm{m} M$ & Maximum degradation $^{2}$ & Rate of degradation ${ }^{3}$ & Lag time, $\mathrm{h}$ \\
\hline \multicolumn{4}{|c|}{ R. flavefaciens B34b } \\
\hline 0 & $18.24 \pm 1.10$ & $0.885 \pm 0.30$ & $15.94 \pm 3.78$ \\
\hline 0.02 & $16.87 \pm 1.22$ & $0.479 \pm 0.20$ & $9.14 \pm 4.05$ \\
\hline 0.04 & $17.25 \pm 1.19$ & $0.542 \pm 0.18$ & $11.02 \pm 3.75$ \\
\hline 0.08 & $19.24 \pm 0.94$ & $0.729 \pm 0.16$ & $12.61 \pm 3.40$ \\
\hline 0.16 & $19.27 \pm 0.95$ & $0.776 \pm 0.18$ & $12.87 \pm 3.42$ \\
\hline 0.32 & $20.83 \pm 1.01$ & $0.743 \pm 0.17$ & $11.90 \pm 3.45$ \\
\hline 0.36 & $18.90 \pm 1.23$ & $0.734 \pm 0.23$ & $15.89 \pm 3.67$ \\
\hline 0.64 & $21.44 \pm 1.17$ & $0.708 \pm 0.21$ & $11.42 \pm 3.69$ \\
\hline Linear & $<0.0001$ & $\mathrm{NC}^{4}$ & 0.9585 \\
\hline Quadratic & 0.3507 & & 0.9850 \\
\hline \multicolumn{4}{|c|}{ R. flavefaciens C94 } \\
\hline 0 & $26.43 \pm 1.58$ & $0.994 \pm 0.23$ & $15.51 \pm 4.57$ \\
\hline 0.02 & $28.58 \pm 1.13$ & $0.742 \pm 0.19$ & $23.62 \pm 3.59$ \\
\hline 0.04 & $28.78 \pm 1.60$ & $0.462 \pm 0.25$ & $8.83 \pm 4.86$ \\
\hline 0.08 & $30.23 \pm 1.47$ & $0.742 \pm 0.29$ & $8.46 \pm 4.67$ \\
\hline 0.16 & $28.51 \pm 1.49$ & $0.579 \pm 0.25$ & $8.83 \pm 4.79$ \\
\hline 0.32 & $35.64 \pm 1.53$ & $1.006 \pm 0.35$ & $14.36 \pm 4.37$ \\
\hline 0.36 & $26.83 \pm 1.74$ & $0.534 \pm 0.26$ & $24.33 \pm 4.60$ \\
\hline 0.64 & $27.74 \pm 1.64$ & $0.464 \pm 0.23$ & $6.74 \pm 4.95$ \\
\hline Linear & $<0.0001$ & $\mathrm{NC}$ & 0.1955 \\
\hline Quadratic & 0.1222 & & 0.0007 \\
\hline
\end{tabular}

${ }^{1}$ For each strain, maximum degradation, rate of degradation, and lag time were evaluated by linear and quadratic contrasts, $P$-values are presented.

${ }^{2} \mathrm{mg}$ of cellulose.

${ }^{3} \mathrm{mg}$ of cellulose/h.

${ }^{4} \mathrm{NC}=$ no contrasts solution; no effect of $\mathrm{Ca}^{+2}$ concentrations $(P>0.05)$.

the equation $\mathrm{Ca}^{+2}=0.5012(\mathrm{Ca})-0.0237$ was obtained, with an $\mathrm{r}^{2}$ value of 0.89 . Thus, approximately $47 \%$ of total $\mathrm{Ca}$ was present as $\mathrm{Ca}^{+2}$.

Possible explanations for the differences between total $[\mathrm{Ca}]$ and $\left[\mathrm{Ca}^{+2}\right]$, even though the source of $\mathrm{Ca}$ was $\mathrm{CaCl}_{2}$, which has $100 \%$ solubility in water, are related to dilution and the presence of constituents in the anaerobic medium that can precipitate or form complexes with Ca. This then affects the electrode response to the $\mathrm{Ca}^{+2}$ in solution. Calcium can form soluble complexes with hydroxide, bicarbonate, polyphosphates, citrate, tartrate, and EDTA, and the extent of this association is greater at both higher $\mathrm{Ca}$ concentrations and higher $\mathrm{pH}$ ( $\mathrm{pH}$ 10-11). Ionized Ca can also form relatively insoluble compounds with oxalate, fluoride, phosphate, and sulfate (ThermoOrion, 2001; manual included with ThermoOrion ion meter), the latter 2 being present in the medium. Temperature is a factor affecting the solubility of different compounds, and because the anaerobic media were sterilized at $120^{\circ} \mathrm{C}$, changes in solubilization, degradation, and reconstitution of the different salts could have been influenced.

Because VFA are produced as fermentation endproducts, $\left[\mathrm{Ca}^{+2}\right]$ was measured in medium with $\mathrm{pH}$ lowered to 4.0 with VFA. Lower $\mathrm{pH}$ did not change the measured values of $\left[\mathrm{Ca}^{+2}\right]$.
A background level of $\mathrm{Ca}$ in the medium could not be avoided because almost all reagent-grade minerals (sodium carbonate, sodium chloride, magnesium sulfate) contain trace amounts of Ca. Also, only the Ca salt of pantothenic acid was available. The deionized water was of similar quality to HPLC water normally used as a reference standard.

Using chelators (EGTA and EDTA) to control $\left[\mathrm{Ca}^{+2}\right]$ was discarded because the pKa of these, approximately 11 for binding $\mathrm{Ca}$ ions, is far above the physiological $\mathrm{pH}$ range of ruminal microorganisms. 1,2-Bis(o-aminophenoxy)ethane-N,N, $\mathrm{N}^{\prime}, \mathrm{N}^{\prime}$-tetraacetic acid (BAPTA) can bind $\mathrm{Ca}^{+2}$ at lower $\mathrm{pH}$ (Tsien, 1980); however, recently, other properties of this product have been recognized that compromise its usefulness as a Ca chelator (Rousset et al., 2004).

\section{Growth Requirements for $\mathrm{Ca}^{+2}$}

Bryant et al. (1959) defined the requirements of FSS85 for several different cations; among these, growth requirements for $\mathrm{Ca}$ and $\mathrm{Mg}$ were determined as a function of maximum absorbance. Growth increased with increasing $\mathrm{Ca}$ concentrations with a reported requirement of $0.25 \mathrm{~m} M$ total Ca. Bryant et al. (1959) did not confirm their Ca concentrations by analysis, only 
Table 6. Cellulose degradation by Fibrobacter succinogenes strains A3c and S85 incubated with different concentrations of $\mathrm{Ca}^{+2}\left[\mathrm{Ca}^{+2}\right]$ and $\mathrm{NH}_{3}$-free media ${ }^{1}$

\begin{tabular}{lccc}
\hline$\left[\mathrm{Ca}^{+2}\right], \mathrm{m} M$ & Maximum degradation $^{2}$ & Rate of degradation $^{3}$ & Lag time, $\mathrm{h}$ \\
\hline F. succinogenes A3c & No degradation & & \\
0 & $3.90($ at $48 \mathrm{~h})$ & 0.11 (estimated) & $<12$ (estimated) \\
0.02 & $7.14 \pm 1.22$ & $0.30 \pm 0.12$ & $10.42 \pm 3.45$ \\
0.04 & $11.23 \pm 1.07$ & $0.42 \pm 0.09$ & $9.95 \pm 2.29$ \\
0.08 & $12.17 \pm 1.21$ & $0.41 \pm 0.09$ & $6.53 \pm 2.41$ \\
0.16 & $11.32 \pm 0.83$ & $0.67 \pm 0.09$ & $9.15 \pm 1.39$ \\
0.32 & $12.08 \pm 1.15$ & $0.50 \pm 0.10$ & $6.92 \pm 2.40$ \\
0.64 & $<0.0001$ & 0.0560 & 0.2030 \\
Linear & $<0.0001$ & 0.0126 & 0.6559 \\
Quadratic & & & \\
F. succinogenes S85 & No degradation & $0.18 \pm 0.08$ & $11.48 \pm 6.88$ \\
0 & $6.67 \pm 1.36$ & $0.39 \pm 0.14$ & $11.07 \pm 3.28$ \\
0.02 & $8.73 \pm 1.45$ & $0.55 \pm 0.06$ & $8.62 \pm 2.16$ \\
0.04 & $10.05 \pm 0.11$ & $0.53 \pm 0.11$ & $12.11 \pm 1.10$ \\
0.08 & $11.26 \pm 1.18$ & $0.51 \pm 0.05$ & $15.95 \pm 0.44$ \\
0.16 & $12.71 \pm 0.59$ & $0.80 \pm 0.03$ & 0.9901 \\
0.32 & $11.03 \pm 0.27$ & 0.0521 & 0.8366 \\
0.64 & 0.0029 & 0.0805 & \\
Linear & 0.2737 & & \\
Quadratic & & & \\
\hline
\end{tabular}

${ }^{1}$ For each strain, maximum degradation, rate of degradation, and lag time were evaluated by linear and quadratic contrasts; $P$-values are presented.

${ }^{2} \mathrm{mg}$ of cellulose.

${ }^{3} \mathrm{mg}$ of cellulose/h.

assuming that the concentration was the amount added to the medium. Subsequently, these have been considered universal for all the rumen bacteria (Scott and Dehority, 1965). It was our goal to evaluate the true $\mathrm{Ca}^{+2}$ requirements of the predominant ruminal cellulolytic bacteria. Results are summarized in Table 7. Our data suggest that the Ca requirements for growth of FS-S85, FS-A3c, and RA-7 may be higher than those reported by Bryant et al. (1959), whereas no requirement could be demonstrated for RF. The present results defined the response to be quadratic for FS-S85, with a higher growth requirement of $0.47 \mathrm{mM} \mathrm{Ca} \mathrm{Ca}^{+2}$. Unfortunately, the latter value lacks precision $\left(\mathrm{r}^{2}\right.$ for the regression $=$ 0.27 ). Growth of RA-7 tended to respond linearly to increasing $\left[\mathrm{Ca}^{+2}\right]$, and it was not possible to establish a requirement for FS-A3c because the data did not fit linear or quadratic functions.

Other studies that evaluated mineral requirements for bacteria from the Bacteroides genus have reported differing responses to the amount of total $\mathrm{Ca}$ in the media. Caldwell et al. (1973) found no effect of Ca on growth of Bacteroides amylophilus (now Ruminobacter amylophilus), and Caldwell and Arcand (1974) observed no effect on Bacteroides ruminicola (now Prevotella ruminicola), but Bacteroides fragilis 2044 and Bacteroides oralis $\mathrm{J} 1$ were sensitive to deletion of $\mathrm{Ca}$ from the growth medium. The addition of $\mathrm{Ca}(28 \mu M)$ to a cation-limited medium did not reestablish normal growth of B. ruminicola ssp. ruminicola B18, B. fragilis ssp. vulgatus 8483, or Bacteroides succinogenes $\mathrm{S} 85$, but if $\mathrm{Mg}(10 \mu M)$ was added, normal growth was observed.

\section{Is Ca Required for Cellulose Degradation?}

Attachment of bacteria to substrate is essential for cellulose degradation, and many authors have studied this process with different experimental approaches. Akin (1976) published morphological studies using the electron microscope, and Minato and Suto (1981) studied the cellulose-binding proteins involved in bacterial attachment to the fiber. Gong and Forsberg (1989) and Roger et al. (1990) evaluated numerous factors in attachment, among them the role of cations.

Gong and Forsberg (1989) reported that adhesion of FS-S85 to cellulose increased abruptly when $27.3 \mathrm{mM}$ $\mathrm{Ca}$ or $20.2 \mathrm{mM} \mathrm{Mg}$ was in the medium. Heat, trypsin, glutaraldehyde, or pronase treatment markedly reduced bacterial adhesion to cellulose, suggesting involvement of a protein, not cations, in adhesion of FS to cellulose. Increasing ionic strength probably improved bacterial adhesion, rather than any specific effect of the cations.

When either $\mathrm{Ca}$ or $\mathrm{Mg}$ was absent, no changes in adhesion of FS-S85 to cellulose were observed by Roger et al. (1990), whereas reduced adhesion was observed for RF-007 when either cation was absent. The effect was greater in the absence of $\mathrm{Mg}$ or $\mathrm{Ca}$ and $\mathrm{Mg}$. Lignin and pectin in plant cell walls bind $\mathrm{Ca}^{+2}$, whereas cellulose does not (Torre et al., 1992). 
Table 7. Summary of $\mathrm{Ca}^{+2}$ requirements $(\mathrm{m} M)$ for growth and cellulose degradation by cellulolytic rumen bacteria, using maximum growth and extent of cellulose degradation as criteria

\begin{tabular}{|c|c|c|c|}
\hline \multirow[b]{3}{*}{ Strain } & \multirow{2}{*}{$\frac{\text { Maximum growth }}{\text { Cellobiose }}$} & \multicolumn{2}{|c|}{ Maximum degradation } \\
\hline & & Cellulose & Cellulose $\mathrm{NH}_{3}$-free \\
\hline & {$\left[\mathrm{Ca}^{+2}\right]$} & {$\left[\mathrm{Ca}^{+2}\right]$} & {$\left[\mathrm{Ca}^{+2}\right]$} \\
\hline Fibrobacter succinogenes A3c & $\mathrm{NE}^{1}$ & $>0.36^{2}$ & $0.42^{2}$ \\
\hline F. succinogenes $\mathrm{S} 85$ & 0.47 & $\mathrm{NE}$ & $>0.64^{2}$ \\
\hline Ruminococcus albus 7 & $>0.64^{3}$ & 0.28 & - \\
\hline R. albus 8 & $\mathrm{NR}^{4}$ & NR & - \\
\hline Ruminococcus flavefaciens B34b & $\mathrm{NE}$ & $>0.64$ & - \\
\hline R. flavefaciens C94 & $\mathrm{NE}$ & $>0.64$ & - \\
\hline
\end{tabular}

Considering the absence of a relationship between the presence of $\mathrm{Ca}$ or $\mathrm{Mg}$ and adhesion of FS to cellulose (Gong and Forsberg, 1989; Roger et al., 1990), and that pectin and lignin but not cellulose are the cell wall components that bind divalent cations (Torre et al., 1992), we conclude that $\mathrm{Ca}^{+2}$ does not have a direct effect on binding of purified cellulose by FS at the unspecific adhesion step of cellulose degradation. The effect of $\mathrm{Ca}^{+2}$ on cellulose degradation could be related to the secretion of enzymes from the bacterial cell, it may function as an intermediate in the attachment of enzyme(s) to cellulose, or it may moderate the amount and activity of the enzymes. Forano et al. (1994) reported a decreased response of endoglucanase (EG) B from FS-S85 when $\mathrm{CaCl}_{2}$ and $\mathrm{MgCl}_{2}$ were absent from the zymogram media, and activity was re-established when $0.5 \mathrm{~m} M$ of these compounds were added to the media. Bera et al. (1996), working with EGC from FS strain BL2, observed a decreased response for its activity when EDTA was included in the media, suggesting a requirement for divalent cations. Although we observed a response to increased $\left[\mathrm{Ca}^{+2}\right]$ for FS-S85 and FS-A3c, our experimental evidence is insufficient to discriminate which mechanisms might be involved.

There is, without doubt, an absolute $\mathrm{Ca}^{+2}$ requirement by FS for cellulose degradation, because neither strain degraded cellulose in the absence of $\mathrm{Ca}^{+2}$. Extents of degradation and lag times were affected by $\mathrm{Ca}^{+2}$ concentrations to different degrees. For maximum degradation, FS-A3c responded linearly and FS-S85 did not reach a solution for contrasts analysis. Lack of solution for FS-S85 may be caused by variation within strains. When growth was excluded from the process by deleting $\mathrm{N}$ from the medium, results confirmed the specific requirement of $\mathrm{Ca}^{+2}$ for cellulose degradation. Both extent and rate of degradation by FS-A3c were significantly affected by $\left[\mathrm{Ca}^{+2}\right]$. The greatest extent of degradation was attained with $0.42 \mathrm{mM} \mathrm{Ca}{ }^{+2}$, whereas the greatest rate of degradation was with $0.39 \mathrm{~m} M$, values that probably are not different. For FS-S85 a linear contrast was significant for both maximum degradation and rate of degradation. When rate of degradation was plotted versus $\left[\mathrm{Ca}^{+2}\right]$, it was readily apparent that maximum rates of degradation were attained when $\mathrm{Ca}^{+2}$ was 0.32 and $0.64 \mathrm{~m} M$ for FS-A3c and FS-S85, respectively, similar in magnitude to values estimated by statistical regression.

As expected, cellulose degradation by RF increased with increased $\mathrm{Ca}^{+2}$ concentrations. Ruminococcus flavefaciens has cellulosome structures with amino acid sequences that bind $\mathrm{Ca}^{+2}$ (Ding et al., 2001; Rincon et al., 2001). Although there is no information for RA-7 using a cellulosome to degrade cellulose, increasing $\left[\mathrm{Ca}^{+2}\right]$ increased maximum degradation and lag time. In contrast, RA-8 did not respond to increasing $\left[\mathrm{Ca}^{+2}\right]$, exhibiting a very slow degradation of cellulose. Because all factors known to be needed by RA- 8 to degrade cellulose were included in the medium (Stack et al., 1983), the possible occurrence of an RA- 8 mutant that lacks the capacity to normally degrade cellulose (Devillard et al., 2004) may explain the lack of response to increased $\left[\mathrm{Ca}^{+2}\right]$ by our culture.

The present results are consistent with the evidence available in the literature. It is reported that $\mathrm{Ca}^{+2}$ binding improves the stability of structures involved, permits the interaction between dockerin domains and catalytic domains, or improves enzymatic activity, as was demonstrated for Clostridium thermocellum (Juy et al., 1992; Choi and Ljungdahl, 1996; Bayer et al., 1998; Shoham et al., 1999). Evidence for the cellulosome as a structure for cellulose degradation by RF comes from studies by Ding et al. (2001) and Rincon et al. (2001). 
With isolated endoglucanase-1 from FS-S85, increasing the concentration of $\mathrm{CaCl}_{2}$ from 1 to $10 \mathrm{mM}$ increased rate of enzyme activity, whereas activity of endoglucanase-2 did not change (McGavin and Forsberg, 1988). Adding $10 \mathrm{~m} M \mathrm{Ca}$ to the medium increased enzymatic activity of a Cel-encoded endoglucanase expressed in Escherichia coli; however, no response was observed when the native cellulolytic enzyme(s) from FS was used (Taylor et al., 1987). Forano et al. (1994) obtained a positive response in enzyme activity of EGB from FS-85 when $0.5 \mathrm{mM} \mathrm{CaCl}$ and $\mathrm{MgCl}_{2}$ were added to the zymogram. These inconclusive data correspond to the varied responses observed for $\mathrm{Ca}^{+2}$ requirements in the present studies.

\section{A Metabolic Role for $\mathrm{Ca}^{+2}$ in Microbes?}

It was long considered that $\mathrm{Ca}^{+2}$ does not have a metabolic role in microbial metabolism (Silver, 1977); its function was relegated to the outer (cell wall) environment of the bacteria. Durand and Kawashima (1980) mention that $\mathrm{Ca}$ is involved in the synthesis and stability of the cell wall, and for this reason, gram-positive bacteria may have higher $\mathrm{Ca}$ and $\mathrm{Mg}$ requirements for cell wall synthesis than gram-negative bacteria. However, no clear results addressing this issue were observed in the present study, in which both FS (gram-negative) and RA (gram-positive) responded to increasing $\mathrm{Ca}^{+2}$ concentrations, whereas RF (gram-positive) did not. However, Beveridge et al. (1982) showed that gramnegative bacteria have lower capacity to bind $\mathrm{Ca}^{+2}$ in the cell envelope, and thus they have a lower reservoir of $\mathrm{Ca}^{+2}$ than gram-positive bacteria. This could explain why gram-negative bacteria are more sensitive to changing $\left[\mathrm{Ca}^{+2}\right]$ in the media. The different responses of RA and RF may be due to differing cell wall compositions of these bacteria and their different capacities to bind ions such as calcium.

Under certain environmental conditions, extracellular $\mathrm{Ca}^{+2}$ acts as a signal that subsequently modifies the internal $\left[\mathrm{Ca}^{+2}\right]$ (Jones et al., 1999). Thus, $\mathrm{Ca}^{+2}$ may mediate the bacterial response as a consequence of changes in osmotic or thermic conditions that drive different processes such as sporulation, encapsulation, motility, and reproduction (Ordal, 1977; Silver, 1977). Escherichia coli, a gram-negative bacteria, requires $\mathrm{Ca}^{+2}$ to signal initiation of the reproduction process, activating the expression of a specific protein, FtsZ, that signals the equator for cell division and allows division to occur (Yu and Margolin, 1997). The pleomorphic cells of FS-A3c that were observed in $\mathrm{Ca}^{+2}$-free media may be related to such mechanisms. For other bacteria, such as Bacillus subtilis, the presence of $\mathrm{Ca}^{+2}$ affects both lag time and activation of the reproduction process. With $\mathrm{Ca}^{+2}$ in the media, bacteria grew normally, whereas in the absence of $\mathrm{Ca}^{+2}$, no growth was observed (Herbaud et al., 1998).

\section{CONCLUSIONS}

If the response from the present experiments is extrapolated to the general rumen ecosystem, considering the ruminal $\left[\mathrm{Ca}^{+2}\right]$ reported by Palmquist et al. (1986) and Wagner et al. (1993), who are the only authors to have measured $\mathrm{Ca}^{+2}$ in rumen fluid, it is not possible to envision a $\mathrm{Ca}^{+2}$ deficiency for microbial growth or cellulolytic activity. Reported $\mathrm{Ca}^{+2}$ concentrations were $0.6 \mathrm{~m} M$ at $0 \mathrm{~h}$ and $1.5 \mathrm{mM}$ at $10 \mathrm{~h}$ (Palmquist et al., 1986); and 1.75, 7, and $0.25 \mathrm{mM}$ for 3,6 , and $12 \mathrm{~h}$ postprandial (Wagner et al., 1993); all higher than the apparent requirements observed in this study. Fluctuations in $\left[\mathrm{Ca}^{+2}\right]$ observed as a consequence of changing ruminal $\mathrm{pH}$ with time after feeding apparently have no consequences for bacterial activity, although the $\mathrm{Ca}^{+2}$ released from different forages or diets and the solubility of the supplemental sources could affect $\left[\mathrm{Ca}^{+2}\right]$ as time after feeding progresses.

Although these studies do not support a requirement for higher ruminal $\left[\mathrm{Ca}^{+2}\right]$ than has been reported, they do support roles for $\mathrm{Ca}^{+2}$ in cellulolytic microbial function that have not been explored adequately. Investigation of these roles may reveal other regulatory aspects of $\mathrm{Ca}^{+2}$ for cellulolytic function in the ruminal environment.

\section{ACKNOWLEDGMENTS}

Salary and research support were provided by state and federal funds appropriated to the Ohio Agricultural Research and Development Center, The Ohio State University. MSM acknowledges research leave from the College of Veterinary Medicine, Universidad de Chile, to undertake these studies. The authors thank D. L. Palmquist for valuable assistance in critical review of this manuscript.

\section{REFERENCES}

Akin, D. E. 1976. Ultrastructure of rumen bacterial attachment to forage cell walls. Appl. Environ. Microbiol. 31:562-568.

Bayer, E. A., J. P. Belaich, Y. Shoham, and R. Lamed. 2004. The cellulosomes: multienzyme machines for degradation of plant cell wall polysaccharides. Annu. Rev. Microbiol. 58:521-554.

Bayer, E. A., H. Chanzy, R. Lamed, and Y. Shoham. 1998. Cellulose, cellulases and cellulosomes. Curr. Opin. Struct. Biol. 8:548-557.

Bera, C., V. Broussolle, E. Forano, and G. Gaudet. 1996. Gene sequence analysis and properties of EGC, a family E (9) endoglucanase from Fibrobacter succinogenes BL2. FEMS Microbiol. Lett. 136:7984. 
Beveridge, T. J., C. W. Forsberg, and R. J. Doyle. 1982. Major sites of metal binding in Bacillus licheniformis walls. J. Bacteriol. 150:1438-1448.

Bryant, M. P., and L. A. Burkey. 1953. Cultural methods and some characteristics of some of the more numerous groups of bacteria in the bovine rumen. J. Dairy Sci. 36:205-217.

Bryant, M. P., and R. N. Doetsch. 1954. A study of actively cellulolytic rod-shaped bacteria of the bovine rumen. J. Dairy Sci. 37:11761183.

Bryant, M. P., I. M. Robinson, and H. Chu. 1959. Observations on the nutrition of Bacteroides succinogenes - A ruminal cellulolytic bacterium. J. Dairy Sci. 42:1831-1847.

Bryant, M. P., N. Small, C. Bouma, and I. M. Robinson. 1958 Characteristics of ruminal anaerobic cellulolytic cocci and Cillobacterium cellulosolvens n. sp. J. Bacteriol. 76:529-537.

Caldwell, D. R., and C. Arcand. 1974. Inorganic and metal-organic growth requirements of the genus Bacteroides. J. Bacteriol. 120:322-333.

Caldwell, D. R., M. Keeney, J. S. Barton, and J. F. Keller. 1973. Sodium and other inorganic growth requirements of Bacteroides amylophilus. J. Bacteriol. 114:782-789.

Chesson, A., and C. W. Forsberg. 1997. Polysaccharide degradation by rumen microorganisms. Pages 329-381 in The Rumen Microbial Ecosystem. 2nd ed. P. N. Hobson and C. S. Stewart, ed. Blackie Academic and Professional, London, UK.

Choi, S. K., and L. Ljungdahl. 1996. Structural role of calcium for the organization of the cellulosome of Clostridium thermocellum. Biochemistry 35:4906-4910.

Dehority, B. A. 1963. Isolation and characterization of several cellulolytic bacteria from in vitro rumen fermentations. J. Dairy Sci. 46:217-222.

Devillard, E., D. B. Goodheart, S. R. Karnaty, E. A. Bayer, R. Lamed, J. Miron, K. E. Nelson, and M. Morrison. 2004. Ruminococcus albus 8 mutants defective in cellulose degradation are deficient in two processive endocellulases, Cel48A and Cel9B, both of which possess a novel modular architecture. J. Bacteriol. 186:136-145.

Ding, S. Y., M. T. Rincon, R. Lamed, J. Martin, S. McRae, V. Aurilia, Y. Shoham, E. Bayer, and H. Flint. 2001. Cellulosomal scaffoldinlike proteins from Ruminococcus flavefaciens. J. Bacteriol 183:1945-1953.

Durand, M., and R. Kawashima. 1980. Influence of minerals in rumen microbial digestion, Pages 375-408 in Digestive Physiology and Metabolism in Ruminants. Y. Ruckebusch and P. Thivend, ed. MTP Press Ltd., Lancaster, UK.

Forano, E., V. Broussolle, G. Gaudet, and J. A. Bryant. 1994. Molecular cloning, expression, and characterization of a new endoglucanase gene from Fibrobacter succinogenes S85. Curr. Microbiol. 28:714 .

Gong, J., and C. W. Forsberg. 1989. Factors affecting adhesion of Fibrobacter succinogenes S85 and adherence defective mutants to cellulose. Appl. Environ. Microbiol. 55:3039-3044.

Herbaud, M.-L., A. Guiseppi, F. Denizot, J. Haiech, and M.-C Kilhoffer. 1998. Calcium signaling in Bacillus subtilis. Biochim. Biophys. Acta 1448:212-226.

Hiltner, P., and B. A. Dehority. 1983. Effect of soluble carbohydrates on digestion of cellulose by pure cultures of rumen bacteria. Appl. Environ. Microbiol. 46:642-648.

Hungate, R. E. 1950. The anaerobic mesophilic cellulolytic bacteria. Bacteriol. Rev. 14:1-49.

Hungate, R. E., and R. J. Stack. 1982. Phenylpropanoic acid: Growth factor for Ruminococcus albus. Appl. Environ. Microbiol. 44:7983.

Jenkins, T. C., and D. L. Palmquist. 1982. Effect of added fat and calcium on in vitro formation of insoluble fatty acid soaps and cell wall digestibility. J. Anim. Sci. 55:957-963.

Jones, H. E., I. B. Holland, H. L. Baker, and A. K. Campbell. 1999 Slow changes in cytosolic free $\mathrm{Ca}^{2+}$ in Escherichia coli highlight two putative influx mechanisms in response to changes in extracellular calcium. Cell Calcium 25:265-274.
Juy, M., A. G. Amit, P. M. Alzari, R. J. Poljiak, M. Claeyssens, P. Beguin, and J. P. Aubert. 1992. Three-dimensional structure of a thermostable bacterial cellulase. Nature 357:89-91.

Lytle, B. L., B. Volkman, W. Westler, M. P. Heckman, and D. Wu 2001. Solution structure of a type I dockerin domain, a novel prokaryotic, extracellular calcium-binding domain. J. Mol. Biol. 307:745-753.

McGavin, M., and C. W. Forsberg. 1988. Isolation and characterization of endoglucanases 1 and 2 from Bacteroides succinogenes S85. J. Bacteriol. 170:2914-2922.

Minato, H., and T. Suto. 1981. Technique for fractioning of bacteria in rumen microbial ecosystem. IV. Attachment of rumen bacteria to cellulose powder and elution of bacteria attached to it. J. Gen. Appl. Microbiol. 27:21-31.

Miron, J., D. Ben-Ghedalia, and M. Morrison. 2001. Invited Review: Adhesion mechanisms of rumen cellulolytic bacteria. J. Dairy Sci. 84:1294-1309.

Mitsumori, M., and H. Minato. 2000. Identification of the cellulosebinding domain of Fibrobacter succinogenes endoglucanase F. FEMS Microbiol. Lett. 183:99-103.

Morales, M. S. 2005. Role of ionized calcium and magnesium in cellulose degradation by ruminal bacteria. PhD Diss. The Ohio State University, Columbus.

Noziere, P., and B. Michalet-Doreau. 2000. Chapter 11. In sacco methods. Pages 233-253 in Farm Animal Metabolism and Nutrition. J. P. F. D'Mello, ed. CAB International Publishing, Reading, UK.

Ohara, H., S. Karita, T. Kimura, K. Sakka, and K. Ohmiya. 2000. Characterization of the cellulolytic complex (cellulosome) from Ruminococcus albus. Biosci. Biotechnol. Biochem. 64:254-260.

Ordal, G. W. 1977. Calcium ion regulates chemotactic behaviour in bacteria. Nature 270:66-67.

Palmquist, D. L., T. C. Jenkins, and A. E. Joyner Jr.. 1986. Effect of dietary fat and calcium source on insoluble soap formation in the rumen. J. Dairy Sci. 69:1020-1025.

Rincon, M. T., S. McRae, J. Kirby, K. Scott, and H. Flint. 2001. EndB, a multidomain family 44 cellulase from Ruminococcus flavefaciens 17, binds to cellulose via a novel cellulose-binding module and another $R$. flavefaciens protein via a dockerin domain. Appl. Environ. Microbiol. 67:4426-4431.

Roger, V., G. Fonty, S. Komisarczuk-Bondy, and P. Gouet. 1990. Effects of physiochemical factors on the adhesion to cellulose avicel of the ruminal bacteria Ruminococcus flavefaciens and Fibrobacter succinogenes. Appl. Environ. Microbiol. 56:3081-3087.

Rousset, M., T. Cens, N. Van Mau, and P. Charnet. 2004. $\mathrm{Ca}^{+2}$ dependent interaction of BAPTA with phospholipids. FEBS Lett. $576: 41-45$.

Russell, J. B. 2002. Rumen Microbiology and Its Role in Ruminant Nutrition. James B. Russell, ed. James B. Russell, Ithaca, NY.

SAS Institute. 1999. SAS/STAT Users's Guide. Version 8. SAS Institute Inc., Cary, NC. OnlineDoc Version 8: http://www.math wpi.edu/saspdf/stat/pdfidx.htm

Scott, H. W., and B. A. Dehority. 1965. Vitamin requirements of several cellulolytic rumen bacteria. J. Bacteriol. 89:1169-1175.

Shoham, Y., R. Lamed, and E. Bayer. 1999. The cellulosome concept as an efficient microbial strategy for the degradation of insoluble polysaccharides. Trends Microbiol. 7:275-281.

Silver, S. 1977. Calcium transport in microorganisms. Pages 49-103 in Microorganisms and Minerals. Microbiology Series Vol. 3. E. D. Weinberg, ed. Marcel Dekker Inc., New York, NY.

Stack, R. J., R. E. Hungate, and W. P. Opsahl. 1983. Phenylacetic acid stimulation of cellulose digestion by Ruminococcus albus 8 . Appl. Environ. Microbiol. 46:539-544.

Taylor, K. A., B. Crosby, M. McGavin, C. W. Forsberg, and D. Y. Thomas. 1987. Characteristics of the endoglucanase encoded by a cel gene from Bacteroides succinogenes expressed in Escherichia coli. Appl. Environ. Microbiol. 53:41-46.

Torre, M., A. R. Rodriguez, and F. Saura-Calixto. 1992. Study of the interactions of calcium ions with lignin, cellulose, and pectin. J. Agric. Food Chem. 40:1762-1766. 
Tsien, R. Y. 1980. New calcium indicators and buffers with high selectivity against magnesium and protons: Design, synthesis and properties of prototype structures. Biochemistry 19:2396-2404.

Ward, G., and L. H. Harbers. 1982. Effect of $\mathrm{pH}$ on extractability of calcium and oxalate from alfalfa leaves. J. Dairy Sci. 65:154160.

Wagner, K. M., J. L. Firkins, M. L. Eastridge, and B. L. Hull. 1993. Replacement of corn silage with wheat middlings and calcium chloride or sodium bicarbonate for lactating dairy cows. J. Dairy Sci. $76: 564-574$

Yu, X. C., and W. Margolin. 1997. $\mathrm{Ca}^{+2}$-mediated GTP-dependent dynamic assembly of bacterial cell division protein FtsZ into asters and polymer networks in vitro. EMBO J. 16:5455-5463.

Zwietering, M. H., I. Jongenburger, F. M. Rombouts, and K. Van't Riet. 1990. Modeling of bacterial growth curves. Appl. Environ. Microbiol. 56:1875-1881. 